\title{
Nematode parasite eggs in pasture soils and pigs on organic farms in Sweden
}

\author{
Kristina Lindgren $(\mathbb{D} \cdot$ Stefan Gunnarsson $(\mathbb{D} \cdot$ \\ Johan Höglund (iD • Cecilia Lindahl (iD) \\ Allan Roepstorff
}

Received: 6 May 2019 / Accepted: 12 November 2019/Published online: 26 November 2019

(C) The Author(s) 2019

\begin{abstract}
The EU regulation for organic pig production requires outdoor access to promote the animal welfare. This may increase the risk of infection of the common pig parasites, Ascaris suum and Trichuris suis, because their eggs can survive for many years in the soil. The egg contamination of these parasites in outdoor areas with different managements and the faecal egg output from the pigs was investigated on 11 Swedish organic pig farms in 2008. We found eggs of A. suum and, to a minor extent, T. suis in the soil from outdoor areas, which had previously
\end{abstract}

The author passed away in 2014.

K. Lindgren $\cdot$ C. Lindahl

RISE Research Institutes of Sweden, P.O. Box 7033, SE-750

07 Uppsala, Sweden

\section{K. Lindgren}

e-mail: kristina.lindgren@ri.se

\section{S. Gunnarsson $(\square)$}

Department of Animal Environment and Health, Swedish University of Agricultural Sciences (SLU), P.O. Box 234, SE-532

23 Skara, Sweden

e-mail: stefan.gunnarsson@slu.se

\section{J. Höglund}

Department of Biomedical Sciences and Veterinary Public Health, Section for Parasitology, Swedish University of Agricultural Sciences (SLU), P.O. Box 7036, SE-750 07 Uppsala, Sweden

\section{A. Roepstorff}

Parasitology and Aquatic Pathobiology, Department of Veterinary and Animal Sciences, Faculty of Life Sciences, University of Copenhagen, Dyrlægevej 100, DK-1870 Frederiksberg C, Copenhagen, Denmark been used for pig rearing and/or for spreading of pig manure. Piglets and their dams were turned out on pastures included in a crop rotation, and these areas had a mean of 2500 A. suum and 40 T. suis eggs per kilogram soil. When the pigs were 12-week-old, the faecal egg counts (FECs) of A. suum were positively correlated with the egg concentration in pasture soils before pig turnout. The areas used by dry sows had a mean of $11,700 \mathrm{~A}$. suum and $220 \mathrm{~T}$. suis eggs per kilogram soil. The highest egg concentrations in the soil were found in areas, frequently used by pigs in the most recent years. To minimise pasture contamination with parasite eggs, it is advised to have a crop rotation system and to inactivate parasite eggs in pig manure before spreading it. Parasite control needs further development to protect suckling piglets from infections due to environmental parasite egg contamination.

Keywords Ascaris suum - Trichuris suis · Organic pigs · Parasite eggs $\cdot$ Transmission on pasture

\section{Introduction}

In conventional indoor pig production with indoor housing, very little or no access to bedding material, and regular prophylactic use of antiparasitic drugs, the impact of most pig helminths on pig health has been reduced (Nansen and Roepstorff 1999). However, pig production systems are changing and excessive use of anthelmintic drugs (dewormers) may lead to selection of parasites that are drug resistant (Roepstorff et al. 2011). The interest for organic pig production has increased in 
Europe over the last decades. In organic production, the pigs are given increased space allowance, bedding material, and access to outdoor areas to promote natural behaviours and welfare. Furthermore, prophylactic use of anthelmintics is not allowed in the organic regulations (EU Council Regulation (EC) No. 834/2007 and Commission Regulation No. 889/2008). Thus, controlled studies as well as practical experience on how to control parasite infections are important for the future of organic pig production (Roepstorff and Mejer 2001).

Most pig nematodes cause subclinical infection that can impair feed conversion and growth rate (e.g. Hale and Stewart 1979; Hale et al. 1985). Furthermore, liver white spots induced by migrating Ascaris suum (the large roundworm) larvae cause economic losses through abattoir condemnations of the levers (Stewart 2001). It has been shown that $A$. suum can cause production losses in relation to the magnitude of the lifetime worm burden (Bernardo et al. 1990). Thus, for organic husbandry, it is of importance that neonatal exposure to A. suum may result in high persistent worm numbers (Stankiewicz et al. 1992; Mejer and Roepstorff 2006a) and Trichuris suis (whipworm) may cause bloodstained diarrhoea and even death, when young pigs are heavily exposed (Powers et al. 1960; Jensen and Svensmark 1996).

Outdoor facilities usually provide suitable conditions for the transmission of nematode parasites such as $A$. suum and T. suis (Roepstorff and Nansen 1994; Mejer and Roepstorff 2006a, b). Both types of parasites are transmitted by infective eggs, which can survive for many years in the soil (Müller 1953; Krasnonos 1978; Hill 1957; Burden et al. 1987). However, the accumulation of nematode eggs in the pigs' environment may go on unnoticed for some time although it may result in highly contaminated soils. This can be detrimental in particular to the young pigs (Powers et al. 1960; Jensen and Svensmark 1996). Despite the fact that A. suum eggs reach infectivity within 1-2 summer months during optimal conditions, it has been found that most eggs on pig pastures in Denmark do not become infective until the following year (Kraglund 1999). It has been shown repeatedly that the eggs of $T$. suis develop more slowly than A. suum (Larsen and Roepstorff 1999; Kraglund 1999; Mejer and Roepstorff 2006b) and in general, eggs of T. suis need more than 1 year to become infective on pastures in a temperate climate (Roepstorff and Murrell 1997; Burden and Hammet 1976, 1979).

Previously, surveys of parasite infection in organic pig herds have been conducted in 12 Danish herds
(Roepstorff et al. 1992), in six herds in central Sweden (Christensson 1996), and in four herds in northern Sweden (Beskow et al. 2003). It was found that A. suum was in general the most common species with a prevalence of $50-70 \%$ in 12-week-old pigs and finishers, whereas T. suis had a prevalence of around $10 \%$. Similarly, pigs on organic and free-range farms were more often infected than those on conventional farms in the Netherlands; e.g. A. suum was found on $73 \%, 50 \%$, and $11 \%$ of farms, respectively (Eijck and Borgsteede 2005).

Both infection levels and the soil contamination with parasite eggs in outdoor areas were investigated on organic pig farms in Denmark (Carstensen et al. 2002; Katakam et al. 2016). Unfortunately, the improvement over time in the parasite infection levels in Danish organic pig herds from 1992 (Roepstorff et al. 1992) until 2002 (Carstensen et al. 2002) was not confirmed in the later study by Katakam et al. (2016). Katakam et al. (2016) found infection levels of A. suum, which were similar to those in the earlier survey by Roepstorff et al. (1992), but higher than in Carstensen et al. (2002). Further, the parasite egg concentrations in soil were markedly higher in 2016 compared with the findings in 2002.

Several studies have been performed on the epidemiology of A. suum and T. suis in outdoor pigs through detection of number of eggs in pig faeces (e.g. Roepstorff et al. 1992; Eijck and Borgsteede 2005), but to the authors' knowledge, there are limited scientific studies about the level of parasite eggs in the pigs' environment. In the present study, we investigated the concentration of eggs in pig pasture soils and the different sources of contamination from pigs and spreading of manure. Further, the relationship between soil egg concentrations and faecal egg counts of pigs exposed to the sampled areas was studied. This is essential to give evidence-based recommendations of outdoor area management on organic pig farms.

\section{Materials and methods}

Farm data

Out of all commercial organic pig farms in Sweden with at least 15 sows in 2008 , eleven farms $(\mathrm{A}-\mathrm{K})$ were included in the study, i.e. these farms comprised $65 \%$ of the total number (17) of Swedish farms with organic sows. The farms studied had an average of 74 sows 
placed (min-max 15-175). In Table 1, farm information regarding the size of the pastures for lactating sows and dry sows, the total agricultural area available used as pig pasture, and how many years the farms had been organic is presented. On all farms, the sows were crossbred Landrace and Yorkshire while the boars were Hampshire. On ten farms, the sows farrowed indoors in single farrowing pens with no outdoor area. After 10-14 days, the sows and piglets were moved to a group suckling system. On seven farms (B, C, D, G, H, J, K), the group suckling housing was seasonal; an indoor pen with an outdoor concrete area was used during the cold season (usually from October until April) while a pasture with huts was used in the warm season. On three farms (A, F, I), the suckling housing was outdoors all year around with huts for groups of sows. On one farm (E), both farrowing and lactation were outdoors, where the sows had their own huts in individual paddocks.

On all farms, the sows were moved to the breeding compartment at weaning, while the piglets remained in the pen or pasture. On four farms $(\mathrm{C}, \mathrm{G}, \mathrm{H}, \mathrm{J})$, the pigs were sold at about 12 weeks of age. On farms A, B and I, most of the growing pigs were not moved until slaughter, while the growing pigs on farms D, E, F, and $\mathrm{K}$ were moved to a barn with an outdoor concrete area for the finishing period. All paddocks with lactating sows and growing pigs were included in a crop rotation, usually with 2-6 years between grazing except on farms $\mathrm{H}$ and I where sometimes an area could be used again within the same year. The average grazing area was $551 \mathrm{~m}^{2}$ (minmax 50-1000) per lactating sow.
The dry sows were kept outdoors in huts all year round on farms D, E, and J. On farms A, B, C, F, G, and $\mathrm{H}$, the dry sows were housed in barns with access to outdoor concrete areas during winter and with access to pastures during summer. On the farm I, the dry sows were moved from the barn to huts in the summer and this was also done on farm $\mathrm{K}$ during 3 out of 4 years. The dry sows could be turned out at the same transport corridors (i.e. from stable to pasture), or pastures for several consecutive years, with intervals ranging from $<$ 1 to 4 years. Only the farmers on farms $\mathrm{E}$ and $\mathrm{K}$ always aimed at an interval of at least 2 years. The pasture area used per dry sow was $319 \mathrm{~m}^{2}$ (mean value). One farmer (E) had used regular prophylactic anthelmintics twice a year; however, no anthelmintic treatments were carried out in any herd during the summer 2008.

In 2008, all farms were visited twice, in April-May and in August-September, respectively. Soil samples were collected during the first visit and faecal samples during the second visit. During the first visit, soil was collected from an area that was planned to be used during the summer 2008 by lactating sows with piglets and dry sows, respectively. In addition, one or two areas were sampled if they were suspected to be high-risk areas that had been used by pigs or for spreading of pig manure or water from the manure heap, at least two out of the previous 3 years.

Semi-structured interviews were conducted with the farmers using an interview guide containing questions about the use of their outdoor areas for the last 10 years, regarding whether they had been used as pig pastures in
Table 1 Total agricultural area at the farm available for use as pig pasture (ha/sow), size of pasture for lactating sows and for dry sows ( $\left.\mathrm{m}^{2} / \mathrm{sow}\right)$, and the number of years with organic pig production

\begin{tabular}{lllll}
\hline Farm & $\begin{array}{l}\text { Agricultural area } \\
(\text { ha/sow })\end{array}$ & $\begin{array}{l}\text { Lactating sow pasture } \\
\left(\mathrm{m}^{2} / \text { sow }\right)\end{array}$ & $\begin{array}{l}\text { Dry sow pasture } \\
\left(\mathrm{m}^{2} / \mathrm{sow}\right)\end{array}$ & $\begin{array}{l}\text { Time with organic } \\
\text { pigs (years })\end{array}$ \\
\hline A & 1.5 & 490 & 317 & 9 \\
B & 1.6 & 1000 & 156 & 4 \\
C & 0.6 & 417 & 420 & 3 \\
D & 2.0 & 50 & 50 & 14 \\
E & 2.4 & 1000 & 750 & 10 \\
F & 5.6 & 833 & 203 & 8 \\
G & 2.3 & 611 & 347 & 4 \\
H & 1.0 & 300 & 150 & 9 \\
I & 4.8 & 600 & 600 & 17 \\
J & 6.9 & 999 & 140 & 9 \\
K & 3.4 & 667 & 375 & 8 \\
Mean & 2.9 & 551 & 319 & 8.6 \\
\hline
\end{tabular}


a crop rotation, small soil runs, woodlands, or transport corridors from a stable to a pasture. From the farmers' crop rotation schemes, information was extracted about which year the areas had been used for pigs or for spreading of pig manure or water from the manure heap.

\section{Sampling}

The soil sampling was done every 5-10 steps while walking along a $\mathrm{W}$-shaped route, and soil samples were collected by taking an equal sample from the upper ground layer (diameter $\sim 2 \mathrm{~cm}$ ) at a depth of $\sim 3-4 \mathrm{~cm}$ using an instrument (Fig. 1). Fresh dung was avoided and the sample collection was subsequently repeated in an opposite $\mathrm{W}$-shape, whereby the samplings were randomly distributed over the whole area. For each Wshape route, approximately 50 subsamples were merged into one pooled sample of 400-700 g.

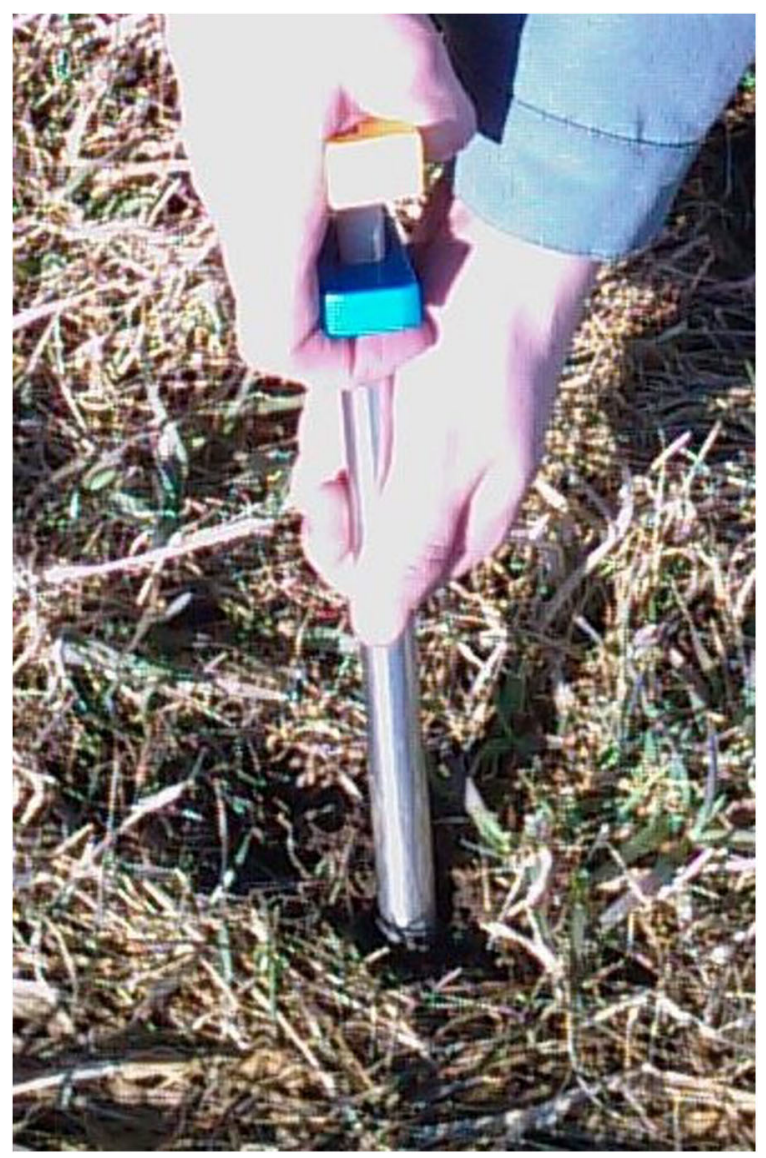

Fig. 1 Pasture soil sampling was performed with a cylindrical metal instrument, inserted in the ground to a depth of 3-4 cm. Photo was taken by Kristina Lindgren
At the second visit, i.e. August-September (late summer), on each farm, faecal samples were collected from 10 pigs at 12 weeks of age, and 10 dry sows. The faecal samples were mostly from the top of freshly deposited faeces (still warm), but occasionally rectal samples were taken from the dry sows. The sampled animals were randomly selected among the groups that had used the areas, which had been soil sampled in the spring. All samples were kept cool in airtight plastic bags until processed.

\section{Laboratory procedures}

In the laboratory, each pooled soil sample was thoroughly mixed, whereupon a 10 -g subsample was soaked in $0.5 \mathrm{M} \mathrm{NaOH}$ overnight, centrifuged several times and then flotated in $3 \mathrm{McMaster}$ slides using saturated $\mathrm{NaCl}$ with $500 \mathrm{~g}$ glucose per litre as a flotation fluid. The helminth eggs recovered were enumerated with a sensitivity of 1 egg per 10-g soil, all according to the method described by Larsen and Roepstorff (1999). The eggs' developmental stage was determined, i.e. eggs with or without developed larvae, and further some eggs were scored to be degenerated (dead).

Faecal egg counts (FECs) were estimated using the concentration McMaster technique (Roepstorff and Nansen 1998) with a lower detection limit of 20 eggs per gramme faeces (EPG) and flotated in the same flotation medium as described above.

Statistical analyses

The SAS (2004) CORR procedure was used for analysis of the correlations (Pearson) between the initial (spring) contamination on pasture and the shedding of eggs later in the season. Calculations were done using the natural $\operatorname{logarithm}(\ln )$ of the number of eggs/10-g soil + 1 and of the $\mathrm{EPG}+1$.

\section{Results}

Nematode eggs in soil

Soil sampling was done from a total of 28 different areas on the eleven farms. From each area, two pooled samples were collected except for a single pooled sample from a very short $(\sim 5 \mathrm{~m})$ transport corridor (from a stable to a pasture). Eggs of A. suum were found in $79 \%$ 
(22) of the areas, whereas T. suis was found in 57\% (16) of the areas. In $18 \%$ (5) of the investigated areas, no nematode eggs were detected. All areas where nematode eggs were found, except for one, contained eggs with developed larvae, either A. suum or T. suis eggs or both. Because the soil samples were collected in the spring, before pig turnout, most of the areas had been rested from pigs at least during the last winter. There were two exceptions: the dry sow pasture on farm I, which had been used previously the same winter, and a pasture on farm E, which had been visited by escaped pigs (weaners running under the fence wire) from a neighbouring pig paddock (Tables 2 and 3). All areas were pastures within a crop rotation system, except for a transport corridor on farm $\mathrm{G}$, one small area with bare soil on farm $\mathrm{J}$, and one woodland area on farm B (Tables 2, 3, and 4).

On nine of the eleven farms, parasite eggs were found in areas which were going to be used for lactating sows and their piglets, whereas on two farms (D and G), no eggs were recovered (Table 2). The soil samples from the pastures contained on average $2.5 \mathrm{~A}$. suum eggs per

Table 2 Pigs 12 weeks. Prevalence (\%) and faecal egg counts expressed as mean egg per gramme faeces (EPG) of Ascaris suum (Asc) and Trichuris suis (Tri) eggs in faeces from 12-week-old weaned pigs in late summer 2008, as well as egg concentrations in replicate soil samples (A, B) collected in the spring 2008 (before 10-g soil (max 11.5 eggs per $10 \mathrm{~g}$ ). A mean of $46 \%$ of these eggs ( $\max 100 \%$ ) contained larvae and may therefore have been infective; however, these percentages should be regarded with care due to the low numbers of differentiated eggs. There was no consistent difference in the egg concentrations between pastures, which had been used for pigs $(n=4)$, and pastures, on which only spreading of manure/slurry had taken place $(n=6)$. One pasture, which had only been exposed to escaped pigs from neighbouring paddocks, was also contaminated with one egg per 10-g soil of both parasites. The egg concentration of A. suum was considerably higher compared with that of $T$. suis (mean $0.4 \mathrm{eggs} / 10 \mathrm{~g}$, max 2.0 eggs/10 g), of which $75 \%$ contained larvae on the pastures used by lactating sows and piglets.

Nine out of eleven dry sow pastures had previously been stocked with pigs. Two of the pastures on farms B and $\mathrm{H}$ had high egg concentrations of $A$. suum (36 and 66 eggs/10 g, respectively), and the farm B pasture also contained the highest number of T. suis (20 eggs/10 g). On four (C, D, F, and $G$ ) of the eleven farms, no nematode eggs were recovered from the pastures, which

pig turnout) from the pastures, which were initially used by lactating sows and then by the growing pigs during the summer 2008 . The percentages of eggs containing larvae as well as the former use of the sampled areas are also shown

\begin{tabular}{|c|c|c|c|c|c|c|c|c|c|c|c|}
\hline \multirow[t]{3}{*}{ Farm } & \multicolumn{2}{|c|}{$\begin{array}{l}\text { Prevalence } \\
(\%)\end{array}$} & \multicolumn{2}{|c|}{$\begin{array}{l}\text { Faecal } \\
\text { EPG }\end{array}$} & \multirow{2}{*}{\multicolumn{2}{|c|}{$\begin{array}{l}\text { Soil eggs/10 } \\
\mathrm{g}\end{array}$}} & \multirow{2}{*}{\multicolumn{2}{|c|}{$\begin{array}{l}\begin{array}{l}\text { Soil eggs/10 } \\
\mathrm{g}\end{array} \\
\text { Tri }\end{array}$}} & \multicolumn{2}{|c|}{$\begin{array}{l}\text { Soil eggs with larvae } \\
(\%)\end{array}$} & \multirow[t]{3}{*}{ Fertilisation and former use of sampled areas } \\
\hline & \multirow[t]{2}{*}{ Asc } & \multirow[t]{2}{*}{ Tri } & \multirow[t]{2}{*}{ Asc } & \multirow[t]{2}{*}{ Tri } & & & & & \multirow{2}{*}{$\begin{array}{l}\text { Asc } \\
\mathrm{A}+\mathrm{B}\end{array}$} & \multirow{2}{*}{$\begin{array}{l}\text { Tri } \\
\mathrm{A}+\mathrm{B}\end{array}$} & \\
\hline & & & & & A & $\mathrm{B}$ & A & B & & & \\
\hline A & 80 & 10 & 718 & 2 & 1 & 3 & 0 & 2 & 100 & 50 & Slurry 2007, 2005, 2004 \\
\hline $\mathrm{B}$ & 70 & 0 & 476 & 0 & 2 & 5 & 0 & 4 & 43 & 100 & Solid pig manure 2002 \\
\hline $\mathrm{C}$ & 10 & 0 & 138 & 0 & 1 & 0 & 0 & 0 & 0 & $\mathrm{n} / \mathrm{a}$ & Solid pig manure 2006 \\
\hline $\mathrm{D}$ & 50 & 0 & 1718 & 0 & 0 & 0 & 0 & 0 & $\mathrm{n} / \mathrm{a}$ & $\mathrm{n} / \mathrm{a}$ & Slurry 2007 \\
\hline $\mathrm{E}$ & 20 & 0 & 174 & 0 & 1 & 0 & 1 & 0 & 0 & 100 & $\begin{array}{l}\text { Next to a paddock with escaping pigs } \\
\text { same year (2008) }\end{array}$ \\
\hline $\mathrm{F}$ & 30 & 0 & 266 & 0 & 0 & 0 & 0 & 1 & $\mathrm{n} / \mathrm{a}$ & 100 & Pig pasture 2001 \\
\hline G & 60 & 0 & 542 & 0 & 0 & 0 & 0 & 0 & $\mathrm{n} / \mathrm{a}$ & $\mathrm{n} / \mathrm{a}$ & Pig pasture 2006, solid pig manure 2007 \\
\hline $\mathrm{H}$ & 50 & 40 & 7612 & 20 & 5 & 3 & 0 & 0 & 25 & 0 & Solid pig manure 2002-2005 \\
\hline I & 100 & 0 & 2538 & 0 & 4 & 19 & 0 & 1 & 100 & 100 & Pig pasture whole year from 2004 to 2005 \\
\hline $\mathrm{J}$ & 80 & 0 & 944 & 0 & 1 & 2 & 0 & 0 & 67 & $\mathrm{n} / \mathrm{a}$ & Solid pig manure 2004, 2003 \\
\hline $\mathrm{K}$ & 90 & 20 & 4308 & 6 & 3 & 4 & 0 & 0 & 29 & $\mathrm{n} / \mathrm{a}$ & $\begin{array}{l}\text { Pig pasture } 2004,2000, \text { water from } \\
\text { manure heap } 2006,2003\end{array}$ \\
\hline Mean & 58 & 6 & 1767 & 3 & 2.5 & & 0.4 & & 46 & 75 & \\
\hline
\end{tabular}


Table 3 Dry sows. Prevalence (\%) and faecal egg counts expressed as mean egg per gramme faeces (EPG) of Ascaris suum (Asc) and Trichuris suis (Tri) eggs in faeces from dry sows in late summer 2008, as well as egg concentrations in replicate soil samples (A, B) collected in the spring 2008 (before pig turnout) from the pastures, which were then used by the dry sows during the summer 2008. The percentages of eggs containing larvae as well as the former use of the sampled areas are also shown

\begin{tabular}{|c|c|c|c|c|c|c|c|c|c|c|c|}
\hline \multirow[t]{3}{*}{ Farm } & \multicolumn{2}{|c|}{$\begin{array}{l}\text { Prevalence } \\
(\%)\end{array}$} & \multicolumn{2}{|c|}{$\begin{array}{l}\text { Faecal } \\
\text { EPG }\end{array}$} & \multirow{2}{*}{$\begin{array}{l}\text { Soil eggs/ } \\
10 \mathrm{~g} \\
\text { Asc }\end{array}$} & \multicolumn{2}{|c|}{$\begin{array}{l}\text { Soil } \\
\text { eggs/10 } \\
\mathrm{g}\end{array}$} & \multicolumn{2}{|c|}{$\begin{array}{l}\text { Soil eggs with } \\
\text { larvae }(\%)\end{array}$} & \multicolumn{2}{|c|}{ Fertilisation and former use of sampled areas } \\
\hline & \multirow[t]{2}{*}{ Asc } & \multirow[t]{2}{*}{$\operatorname{Tr} i$} & \multirow[t]{2}{*}{ Asc } & \multirow[t]{2}{*}{ Tri } & & & \multicolumn{2}{|l|}{ Tri } & \multirow{2}{*}{$\begin{array}{l}A s c \\
\mathrm{~A}+\mathrm{B}\end{array}$} & \multirow{2}{*}{$\begin{array}{l}\text { Tri } \\
\mathrm{A}+\mathrm{B}\end{array}$} & \\
\hline & & & & & A & $\mathrm{B}$ & A & $\mathrm{B}$ & & & \\
\hline A & 30 & 10 & 210 & 2 & 2 & 4 & 2 & 2 & 83 & 75 & Pig pasture whole year from 2001 to 2002 \\
\hline B & 0 & 10 & 0 & 8 & 4 & 68 & 1 & 38 & 0 & 41 & Dry sow woodland 2004-2007 \\
\hline $\mathrm{C}$ & 10 & 0 & 58 & 0 & 0 & 0 & 0 & 0 & $\mathrm{n} / \mathrm{a}$ & $\mathrm{n} / \mathrm{a}$ & Pig pasture 2006 , only 1 sow with piglets \\
\hline $\mathrm{D}$ & 10 & 10 & 16 & 2 & 0 & 0 & 0 & 0 & $\mathrm{n} / \mathrm{a}$ & $\mathrm{n} / \mathrm{a}$ & Slurry $2007^{1}$ \\
\hline $\mathrm{E}$ & 0 & 0 & 0 & 0 & 1 & 0 & 1 & 0 & 0 & 100 & Next to pig paddock with escaping pigs same year $(2008)^{1}$ \\
\hline $\mathrm{F}$ & 20 & 10 & 490 & 88 & 0 & 0 & 0 & 0 & $\mathrm{n} / \mathrm{a}$ & $\mathrm{n} / \mathrm{a}$ & Pig pasture 2007, solid pig manure 2006 \\
\hline $\mathrm{G}$ & 20 & 0 & 58 & 0 & 0 & 0 & 0 & 0 & $\mathrm{n} / \mathrm{a}$ & $\mathrm{n} / \mathrm{a}$ & Pig pasture 2006, 2005 \\
\hline $\mathrm{H}$ & 0 & 0 & 0 & 0 & 55 & 72 & 0 & 1 & 90 & 100 & Pig pasture 2007, 2006 \\
\hline I & 40 & 10 & 14 & 2 & 10 & 7 & 2 & 1 & 100 & 100 & Pig pasture whole year from 2004 to 2005 \\
\hline $\mathrm{J}$ & 0 & 0 & 0 & 0 & 2 & 10 & 0 & 0 & 33 & $\mathrm{n} / \mathrm{a}$ & $\begin{array}{l}\text { Dry sow pasture during } 2 \text { months before } \\
\text { sampling, solid pig manure 2004, } 2003\end{array}$ \\
\hline $\mathrm{K}$ & 10 & 20 & 2 & 34 & 12 & 10 & 0 & 0 & 100 & $\mathrm{n} / \mathrm{a}$ & $\begin{array}{l}\text { Pig pasture 2004, 2000, water from manure } \\
\text { heap 2006, 2003, solid pig manure } 2001\end{array}$ \\
\hline Mean & 13 & 6 & 77 & 12 & 11.7 & 2.2 & & 58 & 83 & & \\
\hline
\end{tabular}

${ }^{1}$ The same samples as in Table 1, since the area was going to be used both for lactating sows with piglets and for dry sows

Table 4 High-risk areas. Concentrations of A. suum (Asc) and T. suis (Tri) eggs and percentages of eggs containing larvae in replicate soil samples $(\mathrm{A}, \mathrm{B})$ in relation to the number of years the farm had produced organic pigs and the former use of the sampled areas. The samples were collected from organic pig farms in Sweden in the spring 2008 (before pig turnout). High-risk areas were defined as areas, which had been used for pigs or for spreading pig manure or manure heap water for 2 of the last 3 years

\begin{tabular}{|c|c|c|c|c|c|c|c|c|}
\hline \multirow[t]{3}{*}{ Farm } & \multirow{3}{*}{$\begin{array}{l}\text { Years with } \\
\text { organic pigs }\end{array}$} & \multirow{2}{*}{\multicolumn{2}{|c|}{$\frac{\text { Soil eggs/10 g }}{\text { Asc }}$}} & \multirow{2}{*}{\multicolumn{2}{|c|}{$\frac{\text { Soil eggs/10 g }}{\text { Tri }}$}} & \multicolumn{2}{|c|}{ Soil egg with larvae (\%) } & \multirow[t]{3}{*}{ Fertilisation and former use of sampled areas } \\
\hline & & & & & & \multirow{2}{*}{$\begin{array}{l}\text { Asc } \\
\mathrm{A}+\mathrm{B}\end{array}$} & \multirow{2}{*}{$\begin{array}{l}\text { Tri } \\
\mathrm{A}+\mathrm{B}\end{array}$} & \\
\hline & & $\mathrm{A}$ & $\mathrm{B}$ & A & $\mathrm{B}$ & & & \\
\hline A & 9 & 2 & 2 & 1 & 0 & 100 & 0 & Pig pasture spring 2007, 2006 all year round \\
\hline $\mathrm{C}$ & 3 & 8 & 28 & 0 & 0 & 50 & $\mathrm{n} / \mathrm{a}$ & Pig pasture 2007, 2005 \\
\hline $\mathrm{C}$ & 3 & 4 & 74 & 1 & 1 & 8 & 0 & Dry sow pasture 2007, 2006, 2005 \\
\hline $\mathrm{E}$ & 10 & 9 & 2 & 1 & 0 & 82 & 0 & Pig pasture 2007, 2006, 2005 \\
\hline G & 4 & 3 & $\mathrm{n} / \mathrm{a}^{1}$ & 1 & $\mathrm{n} / \mathrm{a}^{1}$ & 67 & 0 & Transport corridor, dry sows 2007, 2006, 2005 \\
\hline $\mathrm{H}$ & 9 & 293 & 268 & 1 & 0 & 53 & 100 & Pig pasture 2007, 2006, 2005, 2004 \\
\hline $\mathrm{J}$ & 9 & 55 & 65 & 0 & 2 & 70 & 0 & $\begin{array}{l}\text { Small soil outdoor run for sows (service pens) } \\
\text { 2007, 2006, 2005, } 2004\end{array}$ \\
\hline $\mathrm{K}$ & 8 & 38 & 29 & 2 & 0 & 97 & 100 & $\begin{array}{l}\text { Pig pasture 2001, water from manure heap } 2007 \text {, } \\
2005 \text {, solid pig manure } 2002,2003\end{array}$ \\
\hline Mean & & 58.7 & & 0.7 & & 66 & 29 & \\
\hline
\end{tabular}

\footnotetext{
${ }^{1}$ No replicate samples due to the small size of the high-risk area
} 
were going to be used for dry sows. Table 3 shows the concentrations of eggs in the soil samples on pastures used by dry sows. They had a mean of 12 A. suum eggs/ $10-\mathrm{g}$ soil $(\max 63.5 / 10 \mathrm{~g}$ ), of which $68 \%$ contained larvae, and the corresponding figures for T. suis were 2 eggs/10-g soil (max 20 eggs/10 g), of which $79 \%$ contained larvae.

Eggs of A. suum were also found in several of the additional areas that were sampled because they had either been used by pigs or for spreading of pig manure or manure heap water, at least two out of the last 3 years (Table 4). The mean concentration was 59 eggs/10-g soil (max 281 eggs/10 g), of which $66 \%$ contained larvae. The corresponding figures for $T$. suis were 1 egg/10-g soil, of which $29 \%$ contained larvae.

The relationship between soil egg counts of $A$. suum (eggs/10-g soil) and the number of years a pasture was used by pigs during the last 4 years before the samples were taken is shown in Fig. 2. In general, pastures used every year during the last 4 years had the highest soil egg counts.

Faecal egg counts

All herds had A. suum in the 12-week-old pigs with a mean prevalence of $58 \%$ ( 8 herds had a prevalence $\geq$ $50 \%$ ), while $T$. suis was found in three herds (A, H, and $\mathrm{K})$ with a mean prevalence of $6 \%$ (Table 2 ). In the dry sows, A. suum was found in seven herds (A, C, D, F, G,

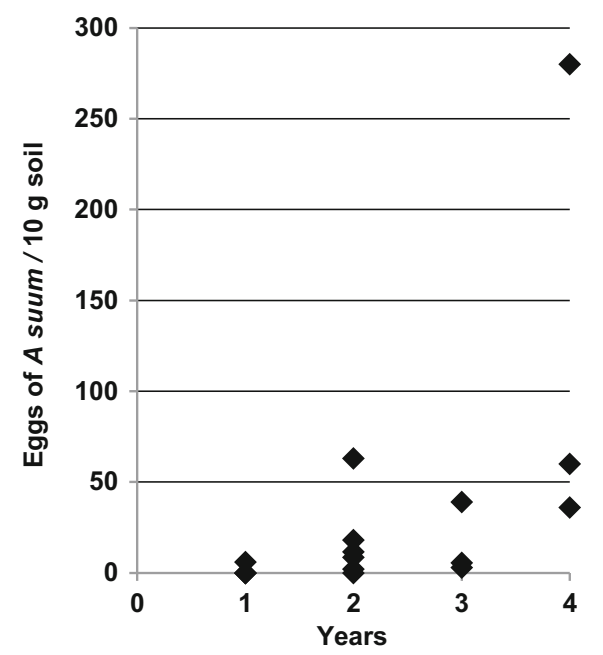

Fig. 2 Soil egg counts of $A$. suum (eggs/10-g soil) at pastures ( $n=$ 16) used by pigs $1-4$ years during the last 4 years before the samples were taken
I, and $\mathrm{K}$ ) and the mean prevalence was $13 \%$ while $T$. suis was found in six herds (A, B, D, F, I, and K) with a mean prevalence of $6 \%$ (Table 3). Mean EPG of A. suum was higher in 12-week-old pigs (mean 1767; min-max 138-7612) than in dry sows (mean 77; min-max 0490), while mean EPG of $T$. suis was somewhat higher in the dry sows (mean 12; min-max $0-88$ ) than in 12week-old pigs (mean 3; min-max 0-20).

There was a positive correlation between the contamination of A. suum eggs on the pasture, before pig turnout in the spring, and the shedding of eggs in late summer for 12-week-old pigs ( $r=0.6 ; P=0.05 ; n=11$ ), while a negative correlation between contamination and egg shedding was found in dry sows $(r=-0.6 ; P=0.03$; $n=11$ ). There was no correlation between pasture contamination in the spring and the egg excretion in late summer for T. suis.

\section{Discussion}

The present study demonstrated that eggs of both $A$. suum and $T$. suis were present in the soil of paddocks used for pig rearing and/or for spreading of pig manure. The egg concentrations in the soils reflected the management system, resulting in high-risk areas, when the management had been suboptimal. Further, the faecal egg counts (FECs) of A. suum in 12-week-old pigs correlated positively with the soil egg concentrations in the pastures where they had been turned out at the age of about 2 weeks.

\section{General contamination}

Before the pigs were turned out on pasture in the present study, A. suum eggs were found on $79 \%$ of the areas, while T. suis eggs were demonstrated on $57 \%$ of the investigated areas $(n=28)$. This is similar to data from five Danish organic pig farms, where the environmental contamination of A. suum eggs was assessed, and 75$100 \%$ of pastures were egg positive for A. suum (Katakam et al. 2016). However, in a previous Danish study on nine farms (Carstensen et al. 2002), only $46 \%$ of soil samples $(n=15)$ collected in March before pig turnout were positive for A. suum and $6 \%$ for T. suis. These nine Danish farms had on average been organic for 2.7 years, but the farm with the longest history of organic outdoor production (8 years) had remarkably high A. suum FECs in the pigs, and one farm with the 
second longest outdoor production (5 years) was also the one with the herd most heavily infected with $T$. suis (Carstensen et al. 2002). An important factor for the higher soil contamination level in the more recent studies is probably the time with outdoor pigs, which for the 5 Danish farms was 7.2 years (Katakam et al. 2016) and for the present study 8.6 years.

In order to be infective, a nematode egg must be fully embryonated, i.e. contain a developed larva (third-stage larva). In the present study, the proportion of larvated nematode eggs in the soil was 59\% for A. suum and 57\% for T. suis. These figures are rather low, when considering the longevity of the eggs. However, this may reflect that the embryonation process on pastures is slow (Burden and Hammet 1979; Roepstorff and Murrell 1997; Larsen and Roepstorff 1999; Kraglund 1999). Thus, most nematode eggs deposited in the late summer/autumn will not embryonate until the temperature rises in May-June of the following year. Despite the different pasture strategies that are described further below, the mean number of larvated A. suum eggs $/ \mathrm{kg}$ dry soil at the pastures for lactating sows in this study was similar to the level at the farrowing pastures on Danish farms (Katakam et al. 2016). Katakam et al. (2016) found 78-171 larvated eggs/kg dry soil, while the mean from pastures for lactating sows in this study was 165 larvated A. suum eggs/kg (range 0-1150).

\section{Sources of soil contamination}

The purpose of the present study was to elucidate sources of parasite egg contamination within soils of pastures on organic pig farms in Sweden. As seen in Tables 2, 3, and 4, the pastures were contaminated either by spreading of pig faeces (solid manure, slurry, or water from manure heaps) or by direct shedding of eggs from pigs or sows with patent infections. A lower egg concentration was found on those pastures exclusively contaminated by spreading of pig manure (Tables 2 and3), than on those with repeated grazing (Tables 2, 3 , and 4). The maximum concentrations of A. suum and T. suis in the soils were $281 \mathrm{eggs} / 10 \mathrm{~g}$ and $20 \mathrm{eggs} / 10 \mathrm{~g}$, respectively. The high level of $A$. suum was probably a result of young pigs being initially exposed to a high contamination-level indoors and then further exposed at pastures used by pigs for several consecutive years. According to our results, pigs at the age of about 12 weeks and older may shed considerable amounts of eggs. Even though the majority of the eggs may die during hot summer days, a large proportion of eggs deposited in autumn can survive in the soil until the next year (Larsen and Roepstorff 1999; Kraglund 1999). The maximum level of $A$. suum in this study was much higher than in the study by Katakam et al. (2016), who found roughly $150 \mathrm{~A}$. suum eggs/10 $\mathrm{g}$ in the soil from pastures for young growers. Young growing pigs and finishers generally have higher levels of both A. suum and T. suis than sows (e.g. Nansen and Roepstorff 1999). This also counts for A. suum in the present study, while $T$. suis showed a more sporadic occurrence (Tables 2 and 3). The average prevalence of A. suum in 12 -week-old pigs was higher $(58 \%)$ than in sows which had a prevalence of $13 \%$.

The lower infection levels in sows together with lower stocking rates is the explanation given by Katakam et al. (2016), who found less A. suum eggs in soil from lactating and dry sow pastures than from pastures for young growers. Hence, the soil contamination reflected differences in infection levels in different age groups as was also seen in a previous Danish study (Carstensen et al. 2002). At Danish organic pig farms, mainly dry sows and sows with suckling piglets were kept on pastures, while after weaning, young pigs were moved to separate pasture areas (Carstensen et al. 2002) or indoors (Carstensen et al. 2002; Katakam et al. 2016). Some farms had pastures for young growing pigs which were mainly used when they could not be accommodated in the stables (Katakam et al. 2016). Furthermore, sow pastures on Danish organic farms were often used during the whole year, whereas in Sweden, the pigs were usually kept indoors with an outdoor concrete area during the cold period. On some Swedish farms, the areas for dry sows had been used year after year, but otherwise, the Swedish organic farmers used a different pasture strategy; i.e. on most farms, lactating sows and growing pigs were kept at pastures, which were incorporated in a crop rotation system with 2-6 years between grazing of the pigs. At weaning, the Swedish sows were moved and the growing pigs remained at the pasture where they had been since the age of 2 weeks. These differences in pasture strategies explain why it was possible to distinguish between pastures that were mainly contaminated by sows and pastures contaminated by growing pigs in the Danish studies but not in this study. At the Swedish farms, it was rather the intensity in the use of the areas, which can explain differences in the level of nematode eggs in the soil. Plotting the mean soil egg counts against the number of 
years a pasture was grazed by infected animals (irrespective of age), indicated that pastures which had been frequently used by pigs within the last few years had the highest soil egg concentrations (Fig. 2).

\section{Egg survival}

Our findings are in accordance with the quantitative plot studies of Larsen and Roepstorff (1999) and Kraglund (1999), where most A. suum and T. suis eggs died within the first few months after deposition; only $0-10 \%$ were recovered after 6 months, leaving a residual population of eggs that survived as long as these studies lasted (1$1 \frac{1}{2}$ year) and probably for $4-10$ years more (Müller 1953; Hill 1957; Krasnonos 1978; Burden et al. 1987). The high initial egg mortality fluctuates systematically with the season, being much more severe for eggs deposited during the summer months than during the remaining part of the year (Larsen and Roepstorff 1999; Kraglund 1999). Therefore, keeping pigs outdoor the year around (information on winter grazing is presented in Tables 2, 3, and 4) and spreading pig faeces (solid manure, etc.) in the autumn, winter, or spring may increase the nematode egg survival substantially. A fatal exposure to T. suis reported by Jensen and Svensmark (1996) happened where a group of weaners was turned out on an outdoor area, on which a heap of straw bedding from the previous group of pigs had been deposited. The old bedding was of great interest to the new pigs (i.e. the pigs were spending time rooting in the straw), and after 4 weeks, approx. $25 \%$ of the pigs had died due to acute infection. Furthermore, in more recent studies, it was observed that eggs of both A. suum (Andersen 2009; Katakam et al. 2016) and T. suis (Andersen 2009) can survive in high numbers in the upper half layer of an organic deep litter area and even though these eggs were undeveloped within the deep litter, they embryonated when moved to favourable conditions for development.

Piglets' and dry sows' exposure to eggs

All areas used by the piglets and their dams in the present study (Table 2) were included in a crop rotation system where the pigs were housed in outdoor huts. Nine of the eleven areas were contaminated with eggs of A. suum and/or T. suis (Table 2). The history of the pastures revealed that only four of them had been used as pig pastures before and three of these not within the last 4 years. However, on eight farms, pig manure had been deposited (solid manure, slurry, or manure heap water) on the pastures. Despite the low egg concentrations in the soil and the limited number of samples, there was a trend for a positive correlation $(r=0.6 ; P=0.051)$ between the A. suum egg concentrations in soil, before pig turnout in the spring of 2008, and the faecal output of A. suum eggs from 12-week-old pigs in the late summer. Due to the low egg concentrations of T. suis in soil and faeces, it was not possible to analyse the spring pasture contamination and faecal egg output for this species.

The piglets in our study were about 2 weeks old when the dams and their piglets were turned out on pastures already contaminated by larvated eggs. Neonatal exposure to A. suum may reduce the immune response to the parasite (e.g. Stankiewicz et al. 1992; Stankiewicz and Froe 1995) and result in higher worm burdens (Mejer and Roepstorff 2006a), than observed when pigs are infected at $8-10$ weeks of age, when the piglets have a more developed immune system (Eriksen et al. 1992). Further, chronic infections with large 'life time worm burdens' increase production losses (Bernardo et al. 1990). This emphasises the importance of using clean pastures for young piglets, as 3-5-weekold piglets can ingest considerable amounts of soil (Mejer and Roepstorff 2006a).

The areas for dry sows in this study had been more intensively used than areas for lactating sows with piglets. Thus, only two sampled areas used by dry sows, on farms $\mathrm{D}$ and $\mathrm{E}$, had not been used as pig pastures before, but the areas on farms F, J, and $\mathrm{K}$ had been used as pig pastures as well as for manure deposition (Table 3 ). This resulted in the generally higher concentrations of both $A$. suum and $T$. suis eggs in spring. There was a negative correlation $(r=-0.6 ; P=0.03)$ between the $A$. suum egg concentrations in the soil, detected before pig turnout in spring, and the faecal output of A. suum eggs from dry sows in the late summer probably because older animals acquire immunity. Mejer and Roepstorff (2006a) noticed elevated levels of serum antibodies and very low FEC levels in the sows during the period when the transmission of A. suum in the piglets increased.

\section{High-risk areas}

Pasture management plans were used to identify potential high-risk areas. On these, the egg concentrations ranged from 0 to 281 eggs/10-g soil for A. suum and 
from 0 to $20 \mathrm{eggs} / 10 \mathrm{~g}$ for T. suis (Tables 3 and 4). The highest concentrations of $A$. suum eggs were found on farm $\mathrm{H}$ in two small areas, which had been used for several consecutive years by litters of piglets (up to 12 weeks of age) and their dams from early spring to late autumn. The same farm also had the highest infection levels of both A. suum and T. suis in young pigs (Table 2). High A. suum egg concentrations were also found in a small run outside the service pens on farm $\mathrm{J}$ (Table 4), which had been used by dry sows the whole year around for the last 4 years. The highest concentration of T. suis eggs was found on farm B on a woodland area, which had been used by dry sows in the grazing seasons of the last 4 years (Table 3 ). This area also had a relatively high concentration of $A$. suum eggs. Since woodlands cannot be ploughed, the aggregated dispersal of nematode eggs (difference between the replicate samples) was more pronounced than in the fields that had been rotated with crops.

In contrast to the heavily contaminated areas, no nematode eggs were found in other suspected highrisk areas on farms $\mathrm{F}$ and $\mathrm{G}$. Contributing factors were probably that farm $\mathrm{F}$ had the second largest available agricultural area/sow, and farm $\mathrm{G}$ had only 4 years with outdoor pigs and the pigs were sold at 12 weeks. Other causes to the variation in egg concentrations in the highrisk areas may be due to the macroclimate (Western Sweden has more precipitation than Eastern Sweden), soil texture (clay retains the humidity better than sandy soils), animal density, and the season for nematode egg deposition (eggs deposited from autumn to spring probably survive better than eggs deposited in the summer) as has been proposed earlier (Larsen and Roepstorff 1999; Kraglund 1999). In this study, high-risk areas were broadly defined as areas, which were used for pigs or for spreading manure within 2 of the last 3 years. However, some high-risk areas were much more exposed to egg deposition than others. A trend was that the most recent and intense grazing generated the most heavily contaminated areas (Fig. 2), emphasising the importance of regular pasture rotation on outdoor pig farms.

\section{Pasture rotation}

Good management can reduce the risk of parasite exposure on organic pig farms. A generally lower prevalence of A. suum, compared with earlier surveys in Denmark, was explained by hygienic improvements and new buildings (Carstensen et al. 2002). Also, Katakam et al. (2016) noticed that the farm with the lowest overall parasite occurrence was the only farm using a strict cleaning regime. When it comes to outdoor production, pasture rotation is clearly a factor of major importance. Katakam et al. (2016) pointed out the following: the history of outdoor production, use of semi-permanent pastures, and stocking rates and possibly climatic changes as important factors for the accumulation of nematode eggs in soil. Carstensen et al. (2002) suggested return of pigs to previously contaminated pastures as a major risk factor. Also, Mejer and Roepstorff (2006a) concluded that strategic pasture rotation schemes are important in the control of A. suum. However, a problem on Danish pig farms is the limited availability of land, which makes it difficult to implement a crop rotation plan of 5-10 years (Roepstorff et al. 2011). This is basically in agreement with the situation on some of the Swedish organic pig farms studied herein, where land limitations and/or wanting to simplify the work with feeding the dry sows was why most farmers kept the dry sows in barns with connected pastures resulting in short rotation intervals. However, at least half of the Swedish farms had areas large enough for a rotation of about 5 years. Despite many years with organic production, the seasonal use of pastures combined with long rotation intervals had resulted in a lower accumulation off eggs compared with the egg concentration on Danish pastures for young growing pigs.

\section{Conclusions}

Eggs of A. suum and/or T. suis were found in the soil, irrespective of if the pastures had previously been used by pigs or only for spreading of pig manure. On all farms during the warm season, the suckling piglets (age 10-14 days) and their dams were housed in huts on fields included in a crop rotation. After weaning, the growing pigs remained on the same pasture. The FECs of A. suum, when the pigs were 12-week-old, correlated positively with the egg concentration in soils sampled before pig turnout. The areas used by dry sows were more intensively used and more contaminated with parasite eggs than the pastures for lactating sows. In general, A. suum was more common than T. suis and the highest soil concentration of $A$. suum eggs was found on pastures used by pigs for several consecutive years in recent times. A crop rotation system and composting the 
pig manure before spreading it on the fields are recommended to minimise pasture contamination with viable parasite eggs.

Acknowledgements The authors gratefully acknowledge the farmers for supplying data and opening up their farms for investigation and the funders for their financial support. This study comprises data from two different projects. Soil samples and crop rotation data were collected within a national project funded by the Swedish Board of Agriculture and faecal samples, and some farm data were collected within the COREPIG project (project no. 1904), one of the eight research projects selected for transnational funding by the partners of the CORE Organic ERA-net project (Sweden: Formas). We also wish to thank Sofia Wiberg for collecting samples and data within the latter project.

Funding Information Open access funding provided by Swedish University of Agricultural Sciences.

\section{Compliance with ethical standards}

The project was approved according to the national regulations on ethical approval on animal research by the local Ethical Committee for Laboratory Animals in Gothenburg (Göteborgs djurförsöksetiska nämnd, diary no. 45-2008).

Conflict of interest The authors declare that they have no conflict of interest.

Open Access This article is distributed under the terms of the Creative Commons Attribution 4.0 International License (http:// creativecommons.org/licenses/by/4.0/), which permits unrestricted use, distribution, and reproduction in any medium, provided you give appropriate credit to the original author(s) and the source, provide a link to the Creative Commons license, and indicate if changes were made.

\section{References}

Andersen SN (2009) Occurrence of free-living helminth eggs and larvae in organic pig farms. Master Dissertation, University of Copenhagen

Bernardo TM, Dohoo IR, Donald A (1990) Effect of ascariasis and respiratory diseases on growth rates in swine. Can J Vet Res 54:278-284

Beskow P, Norqvist M, Lundeheim N, Wallgren P (2003) Utomhusproduktion av grisar i Norrland. Svensk Veterinärtidning $\mathrm{Nr} 4$

Burden DJ, Hammet NC (1976) A comparison of the infectivity of Trichuris suis ova embryonated by four different methods. Vet Parasitol 2:307-311

Burden DJ, Hammet NC (1979) The development and survival of Trichuris suis ova on pasture plots in the south of England. Res Vet Sci 26:66-70
Burden DJ, Hammet NC, Brookes PA (1987) Field observations on the longevity of Trichuris suis ova. Vet Rec 121:43

Carstensen L, Vaarst M, Roepstorff A (2002) Helminth infections in Danish organic swine herds. Vet Parasitol 106:253-264

Christensson DA (1996) Djurmiljö och parasitförekomst i utegrishållning - inventering på 12 gårdar. Jordbruksinformation 5:26-27

Eijck IAJM, Borgsteede FHM (2005) A survey of gastrointestinal pig parasites on free-range, organic and conventional pig farms in The Netherlands. Vet Res Commun 29:407-441

Eriksen L, Nansen P, Roepstorff A, Lind P, Nilsson O (1992) Response to repeated inoculations with Ascaris suum eggs in pigs during the fattening period. Parasitol Res 78:241-246

Hale OM, Stewart TB (1979) Influence of an experimental infection of Trichuris suis on performance of pigs. J Anim Sci 49: 1000-1010

Hale OM, Stewart TB, Marti OG (1985) Influence of an experimental infection of Ascaris suum on performance of pigs. $\mathrm{J}$ Anim Sci 60:220-225

Hill HC (1957) The survival of swine whipworm eggs in hog lots. J Parasitol 43:104

Jensen TK, Svensmark B (1996) Trichuriasis hos udendørs slagtesvin. Veterinaer Information 2:3-7

Katakam KK, Thamsborg SM, Dalsgaard A, Kyvsgaard NC, Mejer H (2016) Environmental contamination and transmission of Ascaris suum in Danish organic pig farms. Parasit Vectors 9:80

Kraglund H-O (1999) Survival, development and dispersal of the free-living stages of Ascaris suum, Oesophagostomum dentatum and Trichuris suis at the pasture. Royal Veterinary and Agricultural University, Copenhagen, Denmark, Dissertation

Krasnonos LN (1978) Prolonged survival of Ascaris lumbricoides L., 1758 ova in the soil in Samarkand. Meditsinskaya Parazitologicya i Parazitarnye Bolezni 47:103-105

Larsen MN, Roepstorff A (1999) Seasonal variation in development and survival of Ascaris suum and Trichuris suis eggs on pastures. Parasitology 119:209-220

Mejer H, Roepstorff A (2006a) Ascaris suum infections in pigs born and raised on contaminated paddocks. Parasitology 133: 305-312

Mejer H, Roepstorff A (2006b) Oesophagostomum dentatum and Trichuris suis infections in pigs born and raised on contaminated paddocks. Parasitology 133:295-304

Müller G (1953) Untersuchungen über die Lebensdauer von Askarideneiern in Gartenerde. Zentrallblatt für Bakteriologie, Parasitenkunde, Infektionskrankheiten und Hygiene 159:377-379

Nansen P, Roepstorff A (1999) Parasitic helminths of the pig: factors influencing transmission and infection levels. Int $\mathrm{J}$ Parasitol 29:877-891

Powers KG, Todd AC, McNutt SH (1960) Experimental infections of swine with Trichuris suis. Am J Vet Res 21:262-268

Roepstorff A, Mejer H (2001) Strategies for parasite control in organic pigs. The 5th NAHWOA Workshop, Rødding, 11-13 November, 2001

Roepstorff A, Murrell KD (1997) Transmission dynamics of helminth parasites of pigs on continuous pasture: Ascaris suum and Trichuris suis. Int J Parasitol 27:563-572 
Roepstorff A, Nansen P (1994) Epidemiology and control of helminth infections in pigs under intensive and nonintensive production systems. Vet Parasitol 54:69-85

Roepstorff A, Nansen P (1998) Epidemiology, diagnosis and control of helminth parasites of swine. FAO Animal Health Manual 3, FAO, Rome, ISSN 1020-5187

Roepstorff A, Jørgensen RJ, Nansen P, Henriksen SA, Skovgaard Pedersen J, Andreasen M (1992) Parasitter hos økologiske svin. In Rapport over projekt finansieret af Jordbrugsdirektoratet under Landbrugsministeriet, Landsudvalget for svin (København, Danmark, Danske Slagterier) p 36

Roepstorff A, Mejer H, Nejsum P, Thamsborg SM (2011) Helminth parasites in pigs: new challenges in pig production and current research highlights. Vet Parasitol 180:72-81

SAS Institute Inc (2004) SAS/STAT® 9.1 user's guide, Cary, North Carolina
Stankiewicz M, Froe DL (1995) Unabbreviated Ascaris suum immunizing infections of piglets lead to immunosuppression and increased numbers of intestinal parasites. Acta Parasitol 40:152-155

Stankiewicz M, Jonas W, Froe DL (1992) Patent infections of Ascaris suum in pigs: effect of previous exposure to multiple, high doses of eggs and various treatment regimens. Int $\mathrm{J}$ Parasitol 22:597-601

Stewart TB (2001) Economics of endoparasitism in pigs. Pig News Inf 22:29-30

Publisher's note Springer Nature remains neutral with regard to jurisdictional claims in published maps and institutional affiliations. 